believed and looked upon as being the causa causans of mental disorder. Moreover, there are not wanting those who consider the fine flower of attainment in the cure of insanity to be the application of serum therapy by intravenous injection, which alone they suggest can control toxic agencies and re-establish the normal bio-chemistry of the vital organs.

After nearly 30 years of experience of mental diseases, zanging considerably over 12,000 cases of all forms and varieties of inkanity - using these terms in the sense interpreted by Mercier-I am convinced that the proper treatment of insanity must be the study of each case upon its merits and that to advocate any special treatment as the exclusively correct method is to establish the "idol of a cult" which subsequent experience will inevitably demolish as has already occurred in the past. Whilst so much and strenuous importance appears to be laid upon either the "drug" treatment, or the so-called hospital treatment, or bed treatment in open places, $I$ feel compelled to enter a protest against any one method and also to regret that, in my opinion and that of many others, too little importance is being attached to the purely mental influences-viz., the influence of one mind upon another, whereby qualities such as insight, tact, common-sense, inspired by a feeling of brotherhood and sympathy, fail to receive due appreciation. These mental influences are qualities which should have a higher recognition in the treatment of the insane, for they alone can suggest lines of thought which will facilitate to him the normal appreciation of the outside world, these alone are capable unobtrusively of controlling disordered volition-both inwardly by encouraging selfcontrol and outwardly by directing conduct along reasonable and right channels. Surely it will be acknowledged that at all times and in all ages of medical knowledge the cure of disease has not been wholly or entirely by physical means, but by a judiciously utilised appeal to reason associated always with the coöperation of the patient. These qualities, in my opinion, have ceased to secure their due and formerly recognised place in dealing with variations of that subtle somet7ing which characterises and distinguishes man-viz., the possession not only of consciousness but of selfconsciousness, the capacity not only of exercising a "will" but of having an outlook into the unknown future of time and life. The impression is left upon my mind that your reviewer is dominated by an "idol."

Claybury, March 31st, 1908.

$$
\text { I am, Sir, yours faithfully, }
$$
ROBERT JONES

\section{THE INTERNATIONAL SOCIETY OF TROPICAL MEDICINE.}

\section{To the Editor of THE LANCET.}

SrR,-I am in receipt of a letter from Professor Nocht, deputy-chairman of the German Society of Tropical Medicine, in which he states that the first meeting of that society will be held on April 15th-16th, 1908, in Hamburg; and that the members of the German society will be very happy to meet members of allied societies from abroad. Professor Nocht has requested me to make this fact known. The opening meeting will take place at 9 A.M. on April 15th in the Institut für Schiffs- und Tropenkrankheiten, Hamburg. I am, Sir, yours faithfully,

$$
\text { G. H. F. NUTtall, }
$$

Cambridge, April_3rd, 1908. Honorary Secretary-General.

\section{WHY SILK?}

\section{To the Eator of THE LANCET.}

SIR,-Silk may be regarded as a type of the material employed for ligatures and sutures which, after burial in the tissues of the human frame, if neither extruded nor removed, persists for many months or even years. The heading of this letter is suggested by perusal in recent surgical literature of the following cases.

In the "Annals of Surgery" for November, 1907, Mr. H. M. Rigby describes the removal by an iliac incision of a calculus impacted in the ureter. The ureter was closed by silk sutures. Symptoms recurred. Another calculus was removed from the ureter and two more calculi were passed per urethram. Each of these last three calculi had as a nucleus a silk ligature. Mr. Rigby now advocates suturing the nreter with calgut. In THE LANCET of March 21st, 1908, in his first Lettsomian lecture, Mr. Charters J. Symonds records five cases of nephrectomy, performed for tuberculosis of the kidney. In four of these cases the behaviour of the igature was as follows.

CASE 1.-Operation in 1907. The pedicle was secured with silk. "The loin sinus did not close till the ligature came away nearly six months after operation."

CASE 2.-Operation in March, 1907. The pedicle was secured with silk. "The drainage-tube was removed in two days and apparently primary union followed." "About six weeks after operation the loin became swollen and a low form of suppuration developed." In November, 1907, there was "a return of miny of the symptoms existing before nephrectomy." "In the absence of bacilli I attributed the symptoms myself to the loin sinus kept up by the pedicle ligature. This was removed under ether."

CASE 4.- Operation in November, 1907. Material of pedicle ligature not stated, but on Jan. 8th, 1908, seven weeks after operation, "the sinus in the loin, though giving little trouble, will no doubt continue to discharge till the ligature comes away."

CASE 5.-Operation in November, 1897. "The ureter, very thickened, was ligatured and the silk brought out through a rubber drain, into which the end of the ureter was drawn. The ligature came away some eight months after operation." I am, Sir, yours faithfully,

Plymouth, March 26th, 1908. C. HAMILTON WHITEFond.

\section{CHOLERA AND PLAGUE IN THE HEDJAZ AND ELSEWHERE.}

(By The Brirish Delegate to the Constantinople BOARD OF HEALTH.)

SINCE the time of writing my last letter, published in THE LANCET of Feb. 29th (p. 678) the cholera outbreak in the Hedjaz bas almost completely come to an end. In Mecca no cases were observed after Feb. 8th. In Jeddah, where 113 cases of the disease with 95 deaths had been recorded in the week ending Feb. 2nd, only 15 cases and 25 deaths were seen between Feb. 3rd and 8 th ; on the three following days 5 fresh cases and 8 deaths were registered, and after the 11th not a single case or death appeared to have occurred there. In Yanbo, where 18 cases and as many deaths had occurred in the week ending Feb. 3rd, there were 8 cases and 8 deaths between Feb. 3rd and 13th, 3 cases and 3 deaths between the last-named date and Feb. 20th, and 13 cases with 10 deaths from that date to March 11th.

The total number of cases of cholera in the principal towns of the Hedjaz since the beginning of the epidemic on Dec. 13th last down to March 11th is put at 6378 and that of deaths at 5695 . But these figures do not include the statistics of the outbreak to the north of Medina and in connexion with the Hedjaz railway. They are also probably considerably below the truth, even for the towns to which they refer. Written reports are now being received from the health officers of some of those towns and these furnish some details of interest which supplement the bare figures hitherto alone received by telegraph. Thus in Jeddah there were two periods of the epidemic. In the first, which lasted from Dec. 27th, 1907, to Jan. 7th, 1908, some 20 deaths occurred; these all resulted from infection imported by four pilgrims' ships arriving at Jeddah from Yanbo (as described in an earlier letter). Then from Jan. 7 th to 17 th there was a cholera-free period; on the $17 \mathrm{th}$ the caravans began to arrive back at Jeddah from Mecca and a second and much more severe epidemic period set in which lasted until Feb. 11th. In all, 416 cases of cholera with 379 deaths were registered in Jeddah. Of this total 182 cases occurred among Indian pilgrims, 64 among Turkish, 41 among Bokhariots, 24 among Soudanese, 21 among Russians, 16 among Yemenis, 15 among Afghans, 11 among Tripolitans, and the rest among Chinese, Egyptians, native Arabs (only 8 cases) Algerians, Javanese, Tunisians, Bosniacs, Persians, Europeans, Albanians, and Somalis. The maximum period of the epidemic fell on Jan. 24th. Very few cases were isolated in the barrack which does duty for a hospital in Jeddah. Most of those aftlicted seem to have died in the streets and the sufferings of the pilgrims were greatly increased by torrential rains which fell incessantly for 48 hours. It is stated, however, that the infection did not seem to have been spread by water. The new distilling apparatus which the Turkish Government has put 